\title{
Optimal Capacitor Placement for Loss Reduction in Radial Distribution Feeder
}

\author{
Om Prakash Mahela ${ }^{1}$, Sheesh Ram Ola ${ }^{2}$ Lalit Goyal ${ }^{3}$ \\ ${ }^{I}$ (Graduate Student Member IEEE \& Junior Engineer, RRVPNL, Jaipur, India) \\ ${ }^{2}$ (Director Professional Group Institute, Jaipur, India) \\ 3 (Junior Engineer, Rajasthan Rajya Vidhyut Prasaran Nigam Ltd. Jaipur, India)
}

\begin{abstract}
A distribution system is an interface between the bulk power transmission system and the consumer. Among these systems, radial distribution system is popular because of low cost and simple design. In radial distribution feeders, the voltage at buses reduces and loss increases as moved away from the substation due to insufficient amount of reactive power. The reactive power requirement is provided by the shunt capacitor banks. The most important benefit of capacitor placement is loss reduction, voltage profile improvement, increment of power factor and freeing up the power system capacity. Optimal capacitor placement in distribution systems has been studied for a long time. It is an optimization problem which has an objective to define the optimal sizes and allocations of capacitors to be installed. This paper presents an approach for optimal capacitor banks placement in radial distribution feeders for loss reducction.
\end{abstract}

Keywords - capacitor banks, distribution system, optimal capacitor placement, radial distribution feeder, reactive power, loss reduction.

\section{INTRODUCTION}

The increase in power demand and high load density makes the operation of power system complicated. To provide more capacity margin for the substation to meet load demand, system loss minimization and voltage profile improvement techniques are employed [1]. An important method of controlling bus voltage is by placement of shunt capacitor banks at the buses at both transmission and distribution levels, along lines or at substations and loads. Essentially capacitors are a means of supplying VARs at the point of installation [2]. HT shunt capacitor banks provide the fixed reactive compensation in the network [3]. The purpose of capacitors is to minimize the power and energy losses and to maintain better voltage regulation for load buses and to improve system security. The amount of compensation provided with the capacitors that are placed in the distribution network depends upon the location, size and type of capacitors placed in the system [4].

The problem of optimal reactive power dispatch is directly concerned not only with service quality and reliability of supply, but also with economy and security of the power system. Therefore, the power system reactive power optimization problem result directly influences the power system stability and power quality [5]. A large variety of research work has been done on capacitor placement problem in the past. Om Prakash Mahela et al. [6] presented different techniques of capacitor placement in transmission and distribution system to reduce line losses and voltage stability enhancement. References [7]-[9] have considered optimal capacitor placement in networks using fuzzy logic, [10]-[11] have considered Genetic Algorithm, [12] has considered successive quadratic programming method, [13] has considered the tabu search, [14] has considered the Game Theory, [15]-[16] have considered Ant Colony Optimization and [17] has considered Body Immune Algorithm for optimal Placement of Capacitors.

In this paper, a method is proposed to search for optimal HT shunt capacitor placement in radial distribution feeder. The objective function is to reduce the power loss in the feeder. The constraint is voltage limits. The proposed method is tested on the 9-bus IEEE system using MATLAB for optimum capacitor places and sizes. The simulation results show a considerable reduction in active power losses in the radial distribution feeder under study on the placement of capacitors. The active power losses are calculated for different arrangement and sizing of capacitors.

\section{Optimal Capacitor Placement and Sizing Problem Formulation}

The power flow evaluation includes the calculation of bus voltages and line flows of a network. Associated with each bus, there are four quantities to be determined: the real power, the reactive power, and the voltage magnitude and phase angle. Fig. 1 shows the single line diagram of 9-bus IEEE system. 


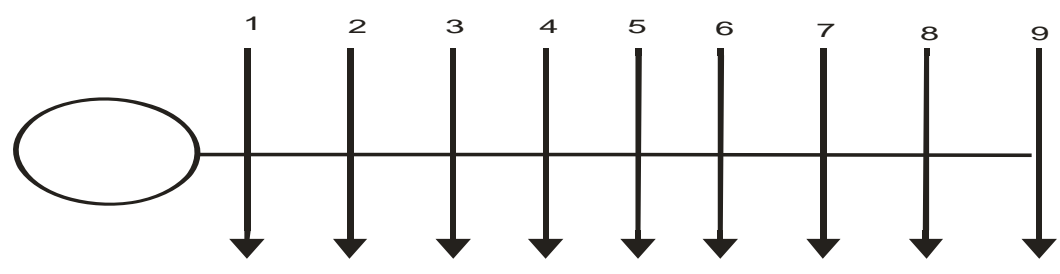

Fig. 1. IEEE 9-bus system

The complex power at the $\mathrm{i}^{\text {th }}$ bus is given by the relation

Where

$$
P_{i}-j Q_{i}=V_{i}^{*} I_{i}
$$

$P_{i}:$ Load active power

$Q_{i}:$ Load reactive power

$V_{i}:$ Voltage at $\mathrm{i}^{\text {th }}$ bus

$I_{i}:$ Load current at $\mathrm{i}^{\text {th }}$ bus

The bus voltage and line losses can be calculated by the Gauss-Seidel iterative method employing the following formula [18]:

Where

$$
V_{i}^{(k+1)}=\frac{1}{Y_{i i}}\left(\frac{P_{i}-j Q_{i}}{V_{i}^{*(k)}}-\sum_{\substack{n=1 \\ n \neq i}}^{m} Y_{i n} V_{n}\right)
$$

$$
\begin{gathered}
V_{i}^{(k)} \text { : Voltage of bus } \mathrm{i} \text { at the } \mathrm{k}^{\text {th }} \text { iteration } \\
P_{i}, Q_{i}: \text { Bus active and reactive power of bus } \mathrm{i} \\
Y_{i m}=\mathrm{y}_{\mathrm{i}, \mathrm{m}} \quad \text { for } \mathrm{i} \neq m \\
\text { and } Y_{i i}=y_{i, m-1}+y_{i, m+1}+y_{c i} \text { for } \mathrm{i}=\mathrm{m}
\end{gathered}
$$

The power loss in the line section between buses $\mathrm{i}$ and $\mathrm{i}+1$, at power frequency can be computed by:

Where

$$
P_{\text {loss }(i, i+1)}=R_{i, i+1}\left[\left|V_{i+1}-V_{i}\right| \cdot\left|y_{i, i+1}\right|\right]^{2}
$$

$y_{i, i+1}=\frac{1}{\left(R_{i, i+1}+X_{i, i+1}\right)}:$ Admittance of the line section between buses $\mathrm{i}$ and $\mathrm{i}+1$.

$R_{i, i+1}$ : Resistance of the line connecting bus $i$ and $i+1$.

$X_{i, i+1}$ : Reactance of the line connecting bus $i$ and $i+1$.

The voltage magnitude at each bus must be maintained within its limits and is expressed as:

$$
V_{\min }<\left|V_{i}\right|<V_{\max }
$$

Where $\left|V_{i}\right|$ is voltage magnitude of $\mathrm{i}^{\text {th }}$ bus. $V_{\min }$ is bus minimum voltage limit. $V_{\max }$ is bus maximum voltage limit. The maximum and minimum voltages limits in the suggested model used are the voltage limits specified by the Indian Electricity Grid Code as given in table-1.

TABLE 1

MAXIMUM AND MINIMUM VOLTAGE LEVEL AS PER IEGC*

\begin{tabular}{|c|c|c|}
\hline \multicolumn{3}{|c|}{ Voltage-(KV rms) } \\
\hline Nominal & Maximum & Minimum \\
\hline 765 & 800 & 728 \\
\hline 400 & 420 & 380 \\
\hline 220 & 245 & 198 \\
\hline 132 & 145 & 122 \\
\hline 110 & 121 & 99 \\
\hline 66 & 72 & 60 \\
\hline 33 & 36 & 30 \\
\hline
\end{tabular}

*Source L-1/18/2010-CERC [19]. 
The purpose of placing compensating capacitors is to obtain the lower total power loss and bring the bus voltages within their specified values. The total power loss is given by the relation:

$$
P_{\text {loss }}=\sum_{i=0}^{m n} P_{\text {loss }(i, i+1)}
$$

\section{OBJECTIVE FUNCTION FORMULATION}

The three-phase system is considered as balanced and loads are assumed as time invariant. Mathematically, the objective function of the problem is minimizing the loss and voltage deviation. This function is:

$$
F=W_{1} \times P_{l o s s}+W_{2} \sum_{i=1}^{m}\left\{\max \left(0, V_{\min }-V_{i}\right)^{2}+\max \left(0, V_{i}-V_{\max }\right)^{2}\right\}
$$

Where

$\mathrm{W}_{1}$ : Objective function coefficient for power loss

$\mathrm{W}_{2}$ : Objective function coefficient for voltage deviation.

$P_{\text {loss }}$ : Total loss in transmission system.

$V_{\min }$ : Minimum permissible bus voltage.

$V_{\text {max }}$ : Maximum permissible bus voltage

\section{Proposed COMPUTATIONAL Algorithm}

The capacitor placement and sizing is provided by calculation of objective function. The simulation has been done on IEEE 9-bus system shown in Fig. 1. In the first case, power flow is calculated without capacitor placement. In the other cases, the power flow is calculated with capacitor placed at different locations. The objective function is calculated in each case, if this function has the tendency of convergence then capacitors are again placed and process is repeated and if there is no tendency of convergence then location and size of capacitors is suggested. The algorithm used for the capacitor placement in this paper is shown in Fig. 2.

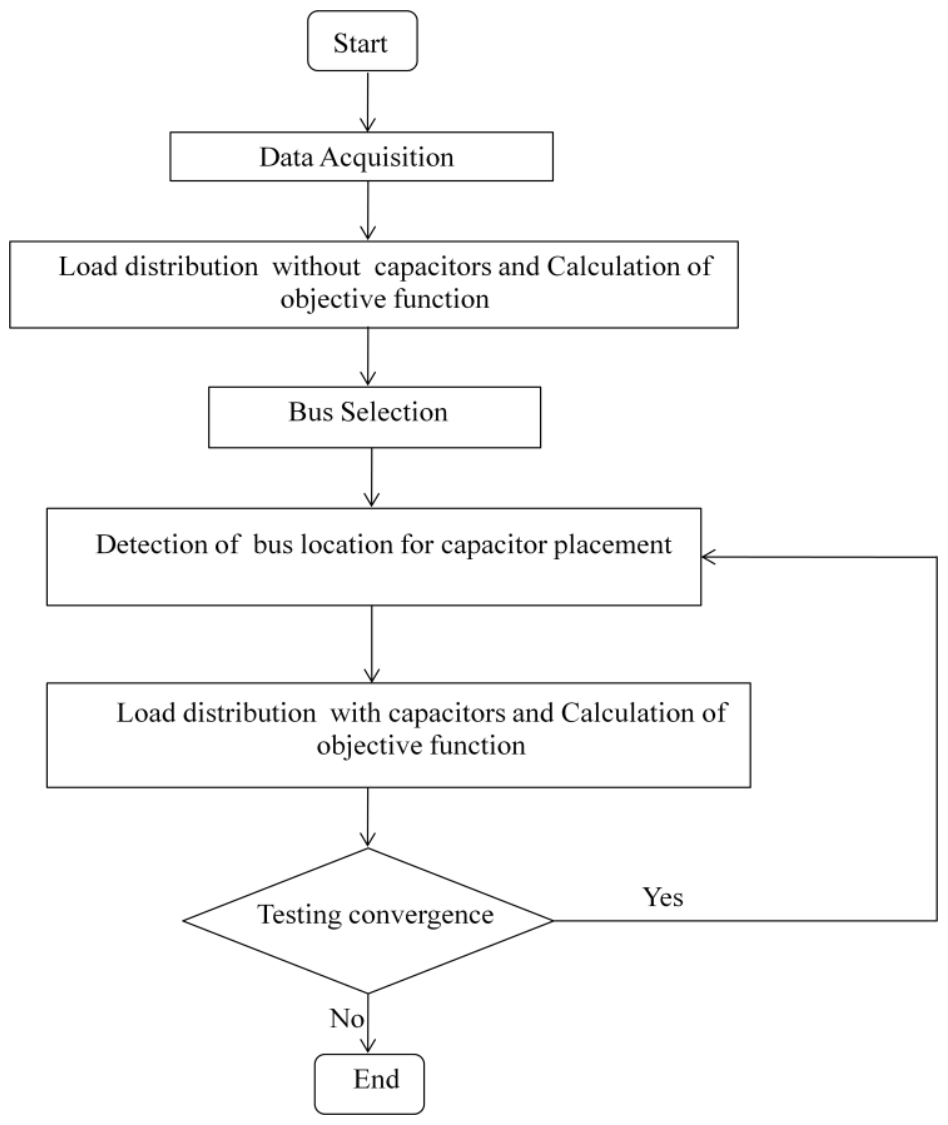

Fig. 2. Flow Chart of Proposed Algorithm for Capacitor placement in Radial Distribution System 


\section{Simulation RESUlTS AND DisCUSSION}

The optimal location and sizing is provided by the objective function. The simulation using MATLAB is carried out on IEEE 9-bus system shown in Fig. 1. The steps of algorithm shown in Fig. 2 are used. The line data set and network buses data set for the 9-bus IEEE system as shown in Table-2, and Table-3 respectively are used [20].

TABLE 2

THE 9-BUS IEEE NETWORK LINE DATA SET

\begin{tabular}{|c|c|c|c|}
\hline Sending End Bus & Receiving End Bus & R (ohm) & X (ohm) \\
\hline 0 & 1 & 0.1233 & 0.4127 \\
\hline 1 & 2 & 0.0140 & 0.6050 \\
\hline 2 & 3 & 0.7463 & 1.2050 \\
\hline 3 & 4 & 0.6984 & 0.6084 \\
\hline 4 & 5 & 1.9831 & 1.7276 \\
\hline 5 & 6 & 0.9053 & 0.7886 \\
\hline 6 & 7 & 2.0552 & 1.1640 \\
\hline 7 & 8 & 4.7953 & 2.7160 \\
\hline 8 & 9 & 5.3434 & 3.0264 \\
\hline
\end{tabular}

TABLE 3

THE 9-BUS IEEE NETWORK BUSES DATA SET

\begin{tabular}{|c|c|c|}
\hline Bus No. & Active Power (P) in KW & Reactive Power (Q) in KVAR \\
\hline 1 & 1840 & 460 \\
\hline 2 & 980 & 340 \\
\hline 3 & 1790 & 446 \\
\hline 4 & 1598 & 1840 \\
\hline 5 & 1610 & 600 \\
\hline 6 & 780 & 110 \\
\hline 7 & 1150 & 60 \\
\hline 8 & 980 & 130 \\
\hline 9 & 1640 & 200 \\
\hline
\end{tabular}

For simulation purposes different cases have been considered. In first case, power flow calculations have been conducted on the network without capacitors. In second and subsequent cases, power flow calculations have been conducted on the network with capacitors of different ratings installed on the different buses. The five different cases with capacitors of different ratings placed at different buses of the radial feeder are studied. The active power losses in the feeder without capacitor placement for first case and with capacitor placement for subsequent cases are shown in Table. 4. The percentage power losses in the feeder in different cases of study are also shown in the Table. 4.

TABLE 4

POWER FLOW RESULTS OF STUDY WITH AND WITHOUT CAPACITORS

\begin{tabular}{|c|l|l|}
\hline $\begin{array}{c}\text { Proposed } \\
\text { Cases }\end{array}$ & $\begin{array}{c}\text { Active Power } \\
\text { Losses (KW) }\end{array}$ & $\begin{array}{c}\text { Active Power } \\
\text { Losses (\%) }\end{array}$ \\
\hline 1 & 1821.75 & 14.73 \\
\hline 2 & 939.41 & 07.59 \\
\hline 3 & 807.72 & 06.53 \\
\hline 4 & 654.60 & 05.26 \\
\hline 5 & 550.62 & 04.45 \\
\hline 6 & 397.06 & 03.21 \\
\hline
\end{tabular}

The size of capacitors at different bus locations in different cases of study are shown in Table. 5. In first case capacitors are not installed at any bus. The sixth case is the result of optimal capacitor placement at different bus locations in the proposed study with optimal capacitor sizing in the IEEE 9-bus radial distribution feeder. 
TABLE 5

CAPACITOR SIZES AT DIFFERENT BUS LOCATIONS IN DIFFERENT CASES OF STUDY

\begin{tabular}{|c|c|c|c|c|c|c|}
\hline $\begin{array}{c}\text { Bus } \\
\text { No. }\end{array}$ & $\begin{array}{c}\text { Case-1 } \\
\text { (Without } \\
\text { Capacitors) }\end{array}$ & $\begin{array}{c}\text { Case-2 } \\
\text { (Capacitors } \\
\text { in KVAR) }\end{array}$ & $\begin{array}{c}\text { Case-3 } \\
\text { (Capacitor } \\
\text { in KVAR) }\end{array}$ & $\begin{array}{c}\text { Case-4 } \\
\text { (Capacitors } \\
\text { in KVAR) }\end{array}$ & $\begin{array}{c}\text { Case-5 } \\
\text { (Capacitors } \\
\text { in KVAR) }\end{array}$ & $\begin{array}{c}\text { Case-6 (Optimal } \\
\text { Capacitor in } \\
\text { KVAR) }\end{array}$ \\
\hline 1 & 0 & 100 & 40 & 60 & 80 & 80 \\
\hline 2 & 0 & 100 & 50 & 50 & 20 & 30 \\
\hline 3 & 0 & 100 & 50 & 50 & 30 & 30 \\
\hline 4 & 0 & 500 & 1600 & 1450 & 1400 & 1350 \\
\hline 5 & 0 & 100 & 100 & 100 & 80 & 90 \\
\hline 6 & 0 & 100 & 50 & 50 & 40 & 50 \\
\hline 7 & 0 & 50 & 0 & 20 & 0 & 0 \\
\hline 8 & 0 & 100 & 50 & 60 & 10 & 0 \\
\hline 9 & 0 & 100 & 100 & 120 & 50 & 40 \\
\hline
\end{tabular}

We conclude from the table (4) that the amounts of active power losses have been reduced when we place some capacitors at appropriate buses in the network. The voltage profile also improves with the placement of capacitors. The optimal sizes of capacitors for minimum active power losses and the minimum voltage deviation from the systems values are obtained in case-6. The suggested optimal sizing of capacitor placement in the network at different bus locations is shown in Table. 5 as case- 6 with optimal capacitors..

\section{CONCLUSION}

The presented results in this paper have shown that the power loss in radial distribution feeder reduces significantly on the placement of capacitors of proper size at appropriate places. The power losses in the feeder were $14.73 \%$ without any capacitors in the network. The losses have reduced to $3.21 \%$ after optimal placement of capacitors. The optimal placement of capacitors in the radial distribution feeder under study has resulted in saving of $11.52 \%$ power.

\section{REFERENCES}

[1] Forough Mahmood Ianfard, Hossein Askarian Abyaneh, and Hamid Reza Salehi, "Optimal capacitor placement for loss reduction," Modern Electric Power Systems, MEPS-10, Wroclaw, Poland, 2010, Paper 11.3.

[2] Anwar S.Siddiqui, and Md. Farrukh Rahman, "Optimal capacitor placement to reduce losses in distribution systems," WSEAS Transactions on Power Systems, Vol. 7, No. 1, January 2012, pp. 12-17.

[3] Om Prakash Mahela, and Sheesh Ram Ola, "Comparison of HT shunt capacitors and SVC for active and reactive power flow control in transmission line," International Journal of Electrical and Electronics Engineering, Vo. 2, No. 1, Feb-2013, pp 49-58.

[4] S.Neelima, and P.S. Subramanyam, "Optimal capacitors placement in distribution networks using genetic algorithm: A dimension reducing approach,” Journal of Theoretical and Applied Information Technology, Vol. 30, No. 1, August 2011, pp. 28-34.

[5] A.H.Mantawy, and M.S.Al-Ghamdi, "A new reactive power optimization algorithm," Proceedings of IEEE Bologna Power Tech Conference, Bologna, Italy, June 23-26,2003.

[6] Om Prakash Mahela, Devendra Mittal, and Lalit Goyal, "Optimal capacitor placement techniques in transmission and distribution networks to reduce line losses and voltage stability enhancement: A review," IOSR Journal of Electrical and Electronics Engineering, Vol. 3, No. 4, Nov-Dec 2012, pp. 01-08.

[7] S.K. Bhattacharya, and S.K. Goswami, "Improved Fuzzy based capacitor placement method for radial distribution system," IEEE Transaction on Power Apparatus and Systems, Vol. 108, No. 4, April 2008, pp. 741-744.

[8] H.N.Ng., N.M.A. Salam, and Y. Chikhani, "Capacitor allocation by approximate reasoning fuzzy capacitor placement," IEEE Transactions on Power Delivery, Vol. 15, No. 1, January 2000, pp. 393-398.

[9] S.M. Khana, A. Rathina Grace Monica, and S.Mary Raja Slochanal, "Fuzzy logic based optimal capacitor placement on radial distribution feeders," IEEE Transaction on Power Apparatus and Systems, Vol. 100, 2007, pp. 1105-1118.

[10] Kenji Iba, "Reactive Power Optimization by Genetic Algorithm," IEEE Transactions on Power Systems, Vol. 9, No. 2, May 1994, pp. 685-692.

[11] L. Furong, J.Pilgrim, C.Dabeedin, A.Cheebo, and R.Aggarwal, "Genetic algorithms for optimal reactive power compensation on the national grid system," IEEE transactions on Power Systems, Vol. 20, No.1, 2005, pp. 493-500.

[12] N. Gridinin, "Reactive power optimization using successive quadratic programming method," IEEE transactions on Power Systems, Vol. 13, No.4, November 1998, pp. 1219-1225.

[13] H.Mori, and Y.Ogita, "Parallel tabu search for capacitor placement in radial distribution systems," Proceedings IEEE Power Engineering Society Winter Meeting, Vol. 4, 2000, pp. 2334-2339.

[14] M.H.Sadeghi, A. Darabi, H. Yassami, M. Owladi, and A. Moeini, "Feasible method for optimal capacitor placement in a distributed system by using game theory," International Journal on Technical and Physical Problems of Engineering (IJTPE), Vol. 3, No. 9, Dec. 2011, pp. 127-131.

[15] Reza Sirjani, and Badiossadat Hassanpour, "A new ant colony based method for optimal capacitor placement and sizing in distribution systems," Research Journal of Applied Sciences, Engineering and Technology, Vol. 4, No. 8, April 2012.

[16] S.Bouri, and A. Zeblah, "Ant colony optimization to shunt capacitor allocation in radial distribution systems," Acta Electrotechnica et Information, Vol. 5, No. 4, 2005.

[17] Majid Davoodi, Mohsen Davoudi, Iraj Ganjkhany, Morteza Arfand, and Ali Aref, "Analysis of capacitor placement in power distribution networks using body immune algorithm," Research Journal of Applied Sciences Engineering and Technology, Vol. 4, No. 17, pp. 3148-3153, 2012. 
[18] Baghzouz, Y., and Ertem, S., "Shunt capacitor sizing for radial distribution feeders with distorted substation voltages," IEEE Transactions on Power Delivery, Vol. 5, No. 2, 1990, pp. 650-657.

[19] L-1/18/2010-CERC, “Central Electricity Regulatory Commission (Indian Electricity Grid Code) Regulations, 2010," Central Electricity Regulatory Commission, New Delhi, India, 2010, pp. 33-38.

[20] Majid Davoodi, Mohsen Davoudi, Iraj Ganjkhany, and Ali Aref, "Optimal capacitor placement in distribution networks using genetic algorithm," Indian Journal of Science and Technology, Vol. 5, No. 7, July 2012, pp. 3054-3058.

\section{BIOGRAPHIES}

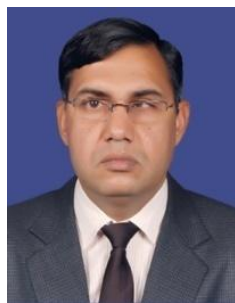

Om Prakash Mahela was born in Sabalpura (Kuchaman City) in the Rajasthan state of India, on April 11, 1977. He studied at Govt. College of Engineering and Technology (CTAE), Udaipur, and received the electrical engineering degree from Maharana Pratap University of Agriculture and Technology (MPUAT), Udaipur, India in 2002. He is currently pursuing M.Tech. (Power System) from Jagannath University, Jaipur, India.

From 2002 to 2004, he was Assistant Professor with the RIET, Jaipur. Since 2004, he has been Junior Engineer-I with the Rajasthan Rajya Vidhyut Prasaran Nigam Ltd., Jaipur, India. His special fields of interest are Transmission and Distribution (T\&D) grid operations, Power Electronics in Power System, Power Quality and Load Forecasting. He is an author of 17 International Journals and Conference papers. He is a Graduate Student Member of IEEE. He is member of IEEE Communications Society. He is Member of IEEE Power \& Energy Society. He is Reviewer of TJPRCInternational Journal of Electrical and Electronics Engineering Research. Mr. Mahela is recipient of University Rank certificate from MPUAT, Udaipur, India, in 2002.

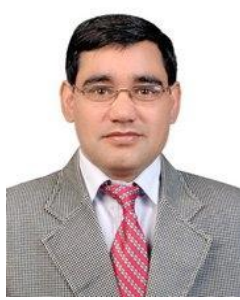

Sheesh Ram Ola was born in Jerthi (Sikar), Rajasthan, India, on June 22, 1975. He studied at Govt. Engineering College, Kota, and received the electrical engineering degree from RU, Jaipur, in 1998. He received M.Tech.(Power System) from MNIT, Jaipur, India in 2001.

From 2001 to 2005, he was Associate Professor and HOD Dept. of Electrical Engineering, RIET, Jaipur. Since 2005, he has been Director with Professional Group (PG) Institute, Jaipur, India. His special fields of interest are Small Electrical Machines, Power Electronics \& Drives, Reactive power management in large grids and Electromagnetic Fields. He is an author of 8 International Journal and Conference Papers. He authored 2 books titled Circuit Analysis \& Synthesis and Basic Electrical Engineering.

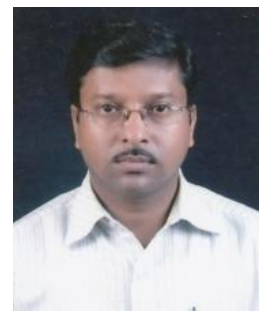

Lalit Goyal was born in Jaipur in the Rajasthan, India, on June 18, 1977. He studied at Govt. College of Engineering and Technology (CTAE), Udaipur and received the electrical engineering degree from Maharana Pratap University, of Agriculture and Technology,Udaipur, India in 2002. He is pursuing M.Tech. (Research) from Jagannath University,Jaipur.

His employment experience included the Rajasthan Rajya Vidhyut Prasaran Nigam Ltd. His special fields of interest are Special Protection Scheme in Power System, Power Transients. 